\title{
Anti-retroviral therapy after "Treat All" in Harare, Zimbabwe: What are the changes in uptake, time to initiation and
}

\section{retention? [version 1; peer review: 2 approved with}

\section{reservations]}

\author{
Takura Matare1, Hemant Deepak Shewade (iD) 2,3, Ronald T. Ncube4, \\ Kudzai Masunda5, Innocent Mukeredzi ${ }^{5}$, Kudakwashe C. Takarinda (D1) 1,3,

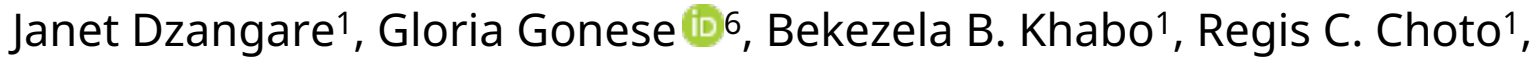 \\ Tsitsi Apollo ${ }^{1}$
}

\footnotetext{
${ }^{1}$ AIDS and TB Unit, Ministry of Health and Child Care, Harare, Zimbabwe

${ }^{2}$ The Union South-East Asia Office, New Delhi, India

${ }^{3}$ International Union Against Tuberculosis and Lung Disease (The Union), Paris, France

${ }^{4}$ The Union Zimbabwe Office, Harare, Zimbabwe

${ }^{5}$ Harare City Health Department, Harare, Zimbabwe

${ }^{6}$ International Training and Education Centre for Health (I-TECH), Harare, Zimbabwe
}

V1 First published: 24 Apr 2020, 9:287

https://doi.org/10.12688/f1000research.23417.1

Latest published: 20 Aug 2020, 9:287

https://doi.org/10.12688/f1000research.23417.2

\section{Abstract}

Background: In Zimbabwe, Harare was the first province to implement "Treat All" for people living with human immunodeficiency virus (PLHIV). Since its roll out in July 2016, no study has been conducted to assess the changes in key programme indicators. We compared antiretroviral therapy (ART) uptake, time to ART initiation from diagnosis, and retention before and during "Treat All".

Methods: We conducted an ecological study to assess ART uptake among all PLHIV newly diagnosed before and during "Treat All". We conducted a cohort study to assess time to ART initiation and retention in care among all PLHIV newly initiated on ART from all electronic patient management system-supported sites $(n=50)$ before and during "Treat All".

Results: ART uptake increased from $65 \%(n=4619)$ by the end of quarter one, 2014 to $85 \%(n=5152)$ by the end of quarter four, 2018. A cohort of 2289 PLHIV were newly initiated on ART before (April-June 2015) and 1682 during "Treat all" (April-june 2017). Their age and gender distribution was similar. The proportion of PLHIV in early stages of disease was significantly higher during "Treat all" (73.2\% vs. $55.6 \%, p<0.001)$. The median time to ART initiation was significantly lower during "Treat All" (31 vs. 88 days, $p<0.001$ ). Cummulative

Open Peer Review
Approval Status
version 2
(revision)
20 Aug 2020
24 Apr 2020
..................................................................
1. Boniface Dongmo-Nguimfack
Health Organization, Geneva, Switzerland
2. Joseph Mugisha Okello iD), Medical
Research Council/Uganda Virus Research
Institute and London School of Hygiene and
Tropical Medicine, Entebbe, Uganda
3. Aneesa Moolla (iD, University of the
Witwatersrand, Johannesburg, South Africa
?iew


retention at three, six and 12 months was consistently lower during "Treat all" and was significant at six months ( $74.9 \%$ vs.78.1\% $\mathrm{p}=0.022)$. Conclusion: Although there were benefits of early ART initiation during "Treat All", the programme should consider strategies to improve retention.

\section{Keywords}

ART outcomes, test and treat, universal test and treat, time to

treatment, HIV, SORT IT, Operational research
Nalini Naidoo, University of the

Witwatersrand, Johannesburg, South Africa

Any reports and responses or comments on the article can be found at the end of the article.

TDRO

Corresponding authors: Takura Matare (takuramatare@gmail.com), Hemant Deepak Shewade (hemantjipmer@gmail.com)

Author roles: Matare T: Conceptualization, Data Curation, Formal Analysis, Investigation, Methodology, Resources, Software, Visualization, Writing - Original Draft Preparation, Writing - Review \& Editing; Shewade HD: Conceptualization, Formal Analysis, Methodology, Software, Visualization, Writing - Original Draft Preparation, Writing - Review \& Editing; Ncube RT: Conceptualization, Formal Analysis, Methodology, Visualization, Writing - Original Draft Preparation, Writing - Review \& Editing; Masunda K: Conceptualization, Data Curation, Writing - Review \& Editing; Mukeredzi I: Conceptualization, Data Curation, Writing - Review \& Editing; Takarinda KC: Conceptualization, Data Curation, Methodology, Software, Writing - Review \& Editing; Dzangare J: Conceptualization, Data Curation, Software, Writing - Review \& Editing; Gonese G: Conceptualization, Data Curation, Writing - Review \& Editing; Khabo BB: Conceptualization, Data Curation, Writing - Review \& Editing; Choto RC: Conceptualization, Project Administration, Supervision, Validation, Writing - Review \& Editing; Apollo T: Conceptualization, Project Administration, Supervision, Validation, Writing - Review \& Editing

Competing interests: No competing interests were disclosed.

Grant information: This research was conducted through the Structured Operational Research and Training Initiative (SORT IT), a global partnership led by the Special Programme for Research and Training in Tropical Diseases at the World Health Organization (WHO/TDR). The training model is based on a course developed jointly by the International Union Against Tuberculosis and Lung Disease (The Union) and Medécins sans Frontières (MSF). The specific SORT IT program which resulted in this publication was implemented by the Centre for Operational Research, The Union, Paris, France. Mentorship and the coordination/facilitation of this particular SORT IT workshop was provided through the Centre for Operational Research, The Union, Paris, France; the Department of Tuberculosis and HIV, The Union, Paris, France; The Union, Zimbabwe Office; The Union, South East Asia Office; and AIDS \& TB Department, Ministry of Health \& Child Care, Harare, Zimbabwe. The training course under which this study was conducted was funded by: the United Kingdom's Department for International Development (DFID); and the World Health Organization Zimbabwe Country Office. Disclaimer: The views represented here are those of the authors and do not represent the institutions they are affiliated to.

The funders had no role in study design, data collection and analysis, decision to publish, or preparation of the manuscript.

Copyright: $@ 2020$ Matare T et al. This is an open access article distributed under the terms of the Creative Commons Attribution License , which permits unrestricted use, distribution, and reproduction in any medium, provided the original work is properly cited.

How to cite this article: Matare T, Shewade HD, Ncube RT et al. Anti-retroviral therapy after "Treat All" in Harare, Zimbabwe: What are the changes in uptake, time to initiation and retention? [version 1; peer review: 2 approved with reservations] F1000Research 2020, 9:287 https://doi.org/10.12688/f1000research.23417.1

First published: 24 Apr 2020, 9:287 https://doi.org/10.12688/f1000research.23417.1 


\section{Introduction}

Globally in 2018, there were an estimated 37.9 million people living with human immunodeficiency virus (PLHIV) ${ }^{1}$. The majority of them $(54 \%)$ are in eastern and southern Africa. Since the start of the epidemic, 32 million people were estimated to have died from acquired immune deficiency syndrome related illnesses ${ }^{1}$. An estimated 23 million people are accessing antiretroviral therapy (ART) globally ${ }^{1}$.

Following evidence from research studies on the clinical and public health benefits of immediate ART, in July 2015, the World Health Organization (WHO) released guidelines on when to start ART and pre-exposure prophylaxis for $\mathrm{HIV}^{2,3}$. These guidelines recommended ART to be offered to all PLHIV ("Treat All"), regardless of $\mathrm{CD} 4$ threshold and/or WHO clinical stage. In July 2018, WHO reported that $84 \%$ of low- and middle-income countries had adopted the "Treat All" policy". Research in other countries demonstrated that after implementation of "Treat All", people on ART had better outcomes ${ }^{2,5-8}$.

Zimbabwe has a generalized HIV epidemic, with an estimated 1.3 million PLHIV and an HIV prevalence of $14 \%$ among adults (15-64 years $)^{9-11}$. In July 2016, Harare province was the first to start implementing "Treat All"12. Since the roll out of "Treat All", no comparative study has been conducted to measure the changes in linkage to care and ART outcomes. We therefore assessed ART uptake, time to ART initiation from diagnosis and retention among PLHIV before and during "Treat All" in Harare.

\section{Methods}

\section{Study design and population}

For ART uptake, we used an ecological design involving aggregate secondary programme data and all PLHIV newly diagnosed before (2014 to June 2016) and during “Treat All” (July 2016 to 2018) in Harare were the study population.

For time to ART initiation and retention, we used a cohort design involving patient wise secondary programme data. We included all PLHIV newly initiated on ART from 50 electronic patient management system (ePMS) sites in Harare before (April-June 2015) and during "Treat All” (April-June 2017).

\section{Study setting}

General setting. Harare province constitutes $16.3 \%$ of the population in Zimbabwe ${ }^{9}$, with an estimated 0.2 million PLHIV, the highest among all the provinces ${ }^{10}$. It has the highest number of patients active on ART, with 77 ART sites providing HIV diagnosis and treatment. As on October 2018, the 50 ePMS sites constituted $52 \%$ of all people on ART in Harare province.

ART initiation before "Treat All". Prior to "Treat All", PLHIV were initiated on ART based on a CD4 eligibility criteria of $<500$ cells $/ \mathrm{mm}^{3}$ (with priority given to those $<300$ cells $/ \mathrm{mm}^{3}$ OR WHO clinical stage 3 or 4 ). Additionally, pregnant and/or breast feeding women, sero-discordant couples, Hepatitis B virus co-infection, people diagnosed with tuberculosis (TB) and children $\leq 5$ years were also eligible irrespective of CD4 count.
Baseline investigations at primary level of care included urine dipstick (glucose, protein), haemoglobin, CD4 count for immunologic staging, cryptococcal antigen screen for adults with CD4 count $<100$ cells $/ \mathrm{mm}^{3}$, screen for pregnancy, syphilis if 12 years or older and hepatitis B infection ${ }^{13}$. Other investigations included full blood count, creatinine and hepatitis $\mathrm{C}$ serology at secondary or tertiary levels of care. PLHIV were screened for active TB and other Opportunistic Infections (OIs) ${ }^{13}$. If active TB was diagnosed, ART was initiated within 2-8 weeks of initiation of anti-TB treatment and within two weeks for advanced TB disease.

Patients were followed up monthly initially and then every three months. Viral load testing targeted those suspected of HIV treatment failure ${ }^{14}$. A patient with confirmed virologic, immunologic or clinical failure were switched to second line ART ${ }^{13}$. Data were routinely recorded in the ART register, patient OI/ART care booklet. The patient level data was also routinely captured electronically in the 50 ePMS sites.

Changes in ART initiation and further management during “Treat All”. All PLHIV are eligible for ART regardless of CD4 count or WHO clinical staging ${ }^{12}$. PLHIV are monitored for viral load at six months after starting ART, 12 months then annually thereafter if stable ${ }^{13}$.

\section{Data variables and sources of data}

For ART uptake, we extracted quarterly aggregate number of new HIV diagnoses and new ART initiations from the District Health Information System 2 (DHIS 2). For time to ART initiation and retention, the source of patient level data was the ePMS and included OI/ART number; ART site; date of HIV diagnosis; date of ART initiation; date of birth; baseline characteristics and outcome at three, six and 12 months - alive and on treatment, death, loss to follow up, stopped ART, transferred out; and date of ART outcome. Operational definition of outcomes has been depicted in Table 1.

\section{Analysis and statistics}

For ART uptake, we calculated quarterly proportions of newly diagnosed PLHIV initiated on ART (Microsoft Excel 2010, Microsoft, Redmond, WA, USA) and presented them using bar diagram and trend lines.

We summarized time to ART initiation after diagnosis using median (interquartile range - IQR) and compared it before and during "Treat All" using Mann Whitney U test. We also used frequency and proportions to summarize time to ART (same day, 2-7 days, 8-14, 15-30 days, 31-90 days, 91-180 days, $>180$ days] and compared it before and during "Treat All" using $\mathrm{z}$ test for proportions. Baseline characteristics and cumulative retention in care were also compared using $\mathrm{z}$ test for proportions (STATA version 12.1, copyright 1985-2011 Stata Corp LP USA).

\section{Ethics}

We obtained ethics approval from the Union Ethics Advisory Group (EAG), Paris, France (EAG number: 47/19, 29 April 2019) and the Medical Research Council of Zimbabwe (MRCZ), Harare 


\section{Table 1. Operational definitions for ART outcomes for PLHIV, Zimbabwe (2015-19).}

\begin{tabular}{|c|c|}
\hline Outcome & Operational Definition \\
\hline $\begin{array}{l}\text { Alive and on } \\
\text { treatment }\end{array}$ & Adults and children with HIV known to be on treatment \\
\hline Transferred out & Documented transfer status in the ePMS/individual ART booklet \\
\hline Died & Documented with a death outcome in the ePMS/individual ART booklet \\
\hline Lost to follow up & $\begin{array}{l}\text { Patients who have not attended their last scheduled review visit or pill } \\
\text { pick-up visit by more than } 90 \text { days from the date of data collection. }\end{array}$ \\
\hline $\begin{array}{l}\text { Stopped } \\
\text { treatment }\end{array}$ & $\begin{array}{l}\text { Documented as having stopped ART in the individual ART booklet, pre- } \\
\text { ART or ART registers }\end{array}$ \\
\hline Attrition & Death, loss to follow up and stopped treatment combined \\
\hline Retained in care & $\begin{array}{l}\text { Alive and on treatment and transferred out combined. Patients that are } \\
\text { transferred out were censored on their last recorded visit to ART site }\end{array}$ \\
\hline
\end{tabular}

HIV: human immunodeficiency virus; PLHIV: people living with HIV; ART: antiretroviral therapy; ePMS: electronic patient management system.

(MRCZ/E/245, 19 August 2019). As this study involved review of existing programme records, we sought and obtained waiver of written informed consent from the ethics committees. Secondary data were extracted after obtaining administrative approval from the concerned authorities.

\section{Results}

\section{ART uptake}

A total of 84,776 people were diagnosed with HIV before (2014 to June 2016) and 82,672 during "Treat All" (July 2016 to 2018). ART uptake increased from $65 \%(n=4619)$ by the end of quarter one, 2014 to $85 \%(n=5152)$ by the end of quarter four, 2018. Starting quarter three, 2016 (implementation of "Treat All"), there was an increasing trend in the new ART initiations, as well as the ART uptake up to quarter two, 2017. Between quarter three, 2017 and quarter four, 2018, there was an increasing trend in ART uptake, which peaked to $85 \%(\mathrm{n}=5152)$ (Figure 1). However, during this period, the absolute number of HIV diagnoses as well as the absolute new ART initiations reduced.

\section{Baseline characteristics among PLHIV newly initiated on ART}

A total of 2289 PLHIV were newly initiated on ART before (AprilJune 2015) and 1682 were newly initiated during "Treat all" (April-June 2017). The median age (in years) for the two groups was similar, 31 (IQR: 27, 41). Gender distribution before and during "Treat all" was also similar (women: $58.6 \%$ vs. $58.3 \%$ respectively). The proportion of people in early stages of disease (WHO clinical stage I or II) was significantly higher during "Treat all" (73.2\% vs. $55.6 \%, \mathrm{p}<0.001)$.

Time to ART initiation from diagnosis

We were not able to calculate the time interval for $41 \%$ of people because of missing dates. Of those with dates available, the median time to ART initiation from diagnosis was significantly lower during "Treat All" when compared to before "Treat all" (31 vs. 88 days, $\mathrm{p}<0.001$ ). ART initiation on the same day $(19.3 \%$ vs. $4.9 \%, \mathrm{p}=<0.001)$ and within 14 days $(25.5 \%$ vs $12.5 \%$, $\mathrm{p}<0.001$ ) was significantly higher during “Treat All” (Table 2).

\section{ART retention}

Retention at three, six and 12 months was consistently lower during "Treat All" compared to before "Treat All". It was significantly lower at six months (74.9\% vs.78.1\% p=0.022) (Table 3$)$.

\section{Discussion}

This is the first study in Zimbabwe that attempts to document the changes in ART initiation and retention before and during "Treat All'. There were three programme relevant findings.

First, ART uptake improved immediately after the implementation of "Treat All" (starting July 2016 ${ }^{12}$ ). When compared to quarter one, 2014 (65\%), ART uptake improved in quarter four, 2018 (85\%). However, there was a drop in the number of PLHIV diagnosed and number of new ART initiations from quarter three, 2017 to quarter four, 2018. The improvement in uptake during this period was not due to increase in annual new ART initiations. It was because of faster falling trends of HIV diagnoses relative to the falling trends of new ART initiations. Hence, the programme should explore the reasons for reduction in new ART initiations and take necessary action to ensure that it moves closer to the second ' 90 ' of UNAIDS 90-90-90 targets by $2020^{15}$.

Second, time to ART initiation significantly reduced during "Treat All" when compared to before "Treat All" (31 vs. 88 days). Though the median time reduced, the proportion initiated on ART on the 


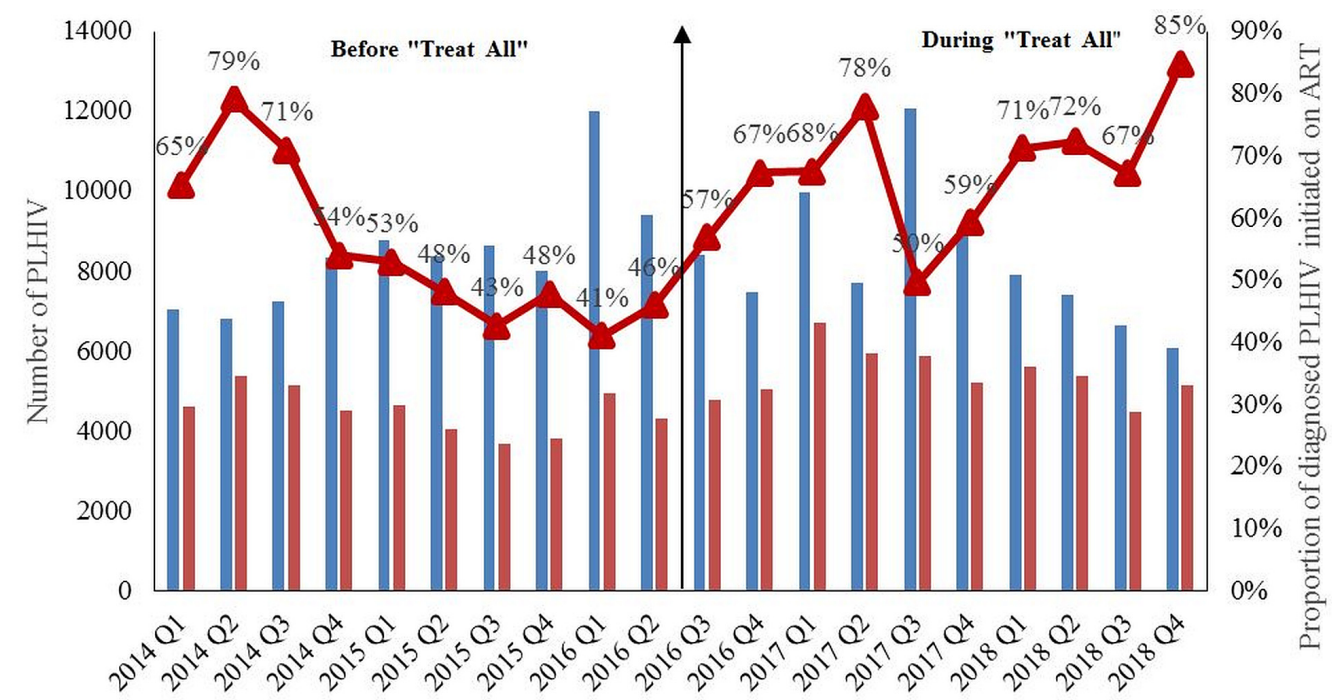

Period

HIV Positive $\quad$ Initiated on ART $\quad-$ Proportion Initiated

Figure 1. Trends" in quarterly ART uptake^ among newly diagnosed PLHIV before (January 2014-June 2016) and during (July 2016December 2018) "Treat All" *, Harare, Zimbabwe. PLHIV: People Living with Human Immunodeficiency Virus; ART: Antiretroviral therapy ^aggregate numbers for each quarter were extracted to calculate ART uptake, source of data is district health information system (DHIS-2) *" Treat All" means all individuals with confirmed HIV diagnosis are eligible for ART irrespective of WHO clinical stage or CD4 count. "During 2014, the CD4 count eligibility criteria was raised from $<350$ to $<500$ cells $/ \mathrm{mm}^{33}$. As more people in pre-ART care were eligible for ART, there was an increase in new ART initiations which resulted in corresponding increase in ART uptake. Similarly, there was an increase in new ART initiations which resulted in corresponding increase in ART uptake after "Treat All".

Table 2. Time to ART initiation from diagnosis among PLHIV newly initiated on ART, before (April-June 2015) and during "Treat All”* (April-June 2017) in 50 ePMS ART sites ${ }^{\wedge}$ in Harare, Zimbabwe.

\begin{tabular}{|l|r|r|r|r|}
$\begin{array}{l}\text { Time to ART } \\
\text { initiation (in days) }\end{array}$ & \multicolumn{2}{l}{$\begin{array}{l}\text { Before "Treat } \\
\text { All” }\end{array}$} & \multicolumn{2}{|l|}{ During "Treat All” } \\
\hline Total & $\mathbf{N}$ & $\mathbf{( \% )}$ & $\mathbf{N}$ & $\mathbf{( \% )}$ \\
\hline Same day & 112 & $(4.9)$ & 325 & $(19.3)$ \\
\hline $2-7$ & 69 & $(3.0)$ & 57 & $(3.5)$ \\
\hline $8-14$ & 106 & $(4.6)$ & 45 & $(2.7)$ \\
\hline $15-30$ & 121 & $(5.3)$ & 59 & $(3.5)$ \\
\hline $31-90$ & 273 & $(11.9)$ & 179 & $(10.6)$ \\
\hline $91-180$ & 292 & $(12.8)$ & 239 & $(14.2)$ \\
\hline$>180$ & 369 & $(16.1)$ & 88 & $(5.2)$ \\
\hline Not recorded & 947 & $(41.4)$ & 690 & $(41.0)$ \\
\hline
\end{tabular}

PLHIV: people living with human immunodeficiency virus; ART: antiretroviral therapy; ePMS: electronic patient management system

*"Treat All" means all individuals with confirmed HIV diagnosis are eligible for ART irrespective of WHO clinical stage or CD4 count.

$\wedge$ As on October 2018, the 50 ePMS sites constituted $52 \%$ of all people on ART in Harare province. 


\begin{abstract}
Table 3. Retention at three, six, and 12 months among PLHIV newly initiated on ART, before (April-June 2015) and during "Treat All”* (AprilJune 2017) in 50 ePMS ART sites ${ }^{\wedge}$ in Harare, Zimbabwe.
\end{abstract}

\begin{tabular}{|c|c|c|c|c|c|}
\hline \multirow[t]{2}{*}{ ART outcomes } & \multicolumn{2}{|c|}{ Before "Treat AlI" } & \multicolumn{2}{|c|}{ During "Treat All" } & \multirow[t]{2}{*}{ P - value } \\
\hline & $\mathbf{N}$ & $\%$ & $\mathbf{N}$ & $(\%)$ & \\
\hline Total & 2289 & $(100.0)$ & 1682 & $(100.0)$ & \\
\hline \multicolumn{6}{|l|}{ Three months } \\
\hline Retained in care & 1905 & $(83.2)$ & 1359 & $(80.8)$ & 0.053 \\
\hline \multicolumn{6}{|l|}{ Attrition } \\
\hline Died & 2 & $(<0.1)$ & 0 & $(0.0)$ & \\
\hline LTFU & 381 & $(16.7)$ & 320 & $(19.0)$ & \\
\hline Stopped ART & 1 & $(<0.1)$ & 3 & $(<0.1)$ & \\
\hline \multicolumn{6}{|l|}{ Six months } \\
\hline Retained in care & 1787 & $(78.1)$ & 1260 & $(74.9)$ & 0.02 \\
\hline \multicolumn{6}{|l|}{ Attrition } \\
\hline Died & 2 & $(<0.1)$ & 0 & $(0.0)$ & \\
\hline LTFU & 499 & $(21.8)$ & 419 & $(24.9)$ & \\
\hline Stopped ART & 1 & $(<0.1)$ & 3 & $(<0.1)$ & \\
\hline \multicolumn{6}{|l|}{12 months } \\
\hline Retained in care & 1667 & $(72.8)$ & 1203 & $(71.5)$ & 0.38 \\
\hline \multicolumn{6}{|l|}{ Attrition } \\
\hline Died & 2 & $(<0.1)$ & 1 & $(<0.1)$ & \\
\hline LTFU & 619 & $(27.1)$ & 475 & (28.3) & \\
\hline Stopped ART & 1 & $(<0.1)$ & 3 & $(<0.1)$ & \\
\hline
\end{tabular}

PLHIV: people living with human immunodeficiency virus; ART: antiretroviral therapy; ePMS: electronic patient management system; LFTU: loss to follow up

*" Treat All" means all individuals with confirmed HIV diagnosis are eligible for ART irrespective of $\mathrm{WHO}$ clinical stage or CD4 count.

$\wedge$ As on October 2018, the 50 ePMS sites constituted $52 \%$ of all people on ART in Harare province.

${ }^{\#}$ Z test of proportions (proportion retained in care)

day of diagnosis was less compared to $65 \%$ in mission hospitals of Zimbabwe in $2017^{16}$. Therefore there is further opportunity to reduce time to linkage to ART. Faster linkage is known to be associated with better retention ${ }^{17}$.

Third, retention did not improve despite more PLHIV being clinically asymptomatic at ART initiation during "Treat All" when compared to before "Treat All". This was contrary to findings in Malawi, where retention at 12 months during "Treat All" $(83 \%)$ was higher than before "Treat All" $(76 \%)^{8}$. In Kenya and Uganda (2017), retention at one year was $89 \%^{17}$. In mission hospitals of Zimbabwe (2017), retention at three months was as high as $90 \%^{16}$. Good health (at diagnosis) has been reported to act both as a barrier as well as a facilitator to ART initiation $^{18,19}$, therefore, we speculate that good health at ART initiation may also act both as a barrier as well as a facilitator to ART retention. Another potential reason for the observed lower retention could be deficiencies in coverage of quality adherence counselling with likely increased work load during the "Treat All" era.
The programme may consider combination intervention strategy to improve linkages to care and retention. This strategy includes i) point-of-care CD4 testing at the time of diagnosis, ii) accelerated ART initiation, and iii) short message service (SMS) health messages and appointment reminder ${ }^{20}$.

The strength of this study were the large sample size, which included all sites in Harare reporting through DHIS 2 and ePMS. There were however some limitations. First, inherent to observational studies is the possibility of documentation errors that could not be validated. Second, some baseline characteristics namely; body mass index, CD4 count, anaemia and Hepatitis B and $\mathrm{C}$ co-infections were incomplete in at least $80 \%$ of the records and were excluded from analysis.

In conclusion, as expected, "Treat All" increased ART uptake and reduced time to ART initiation. Retention in care did not improve as a result of "Treat all". This is a clarion call for the programme to focus interventions on efficient linkage to ART and retention in care in order to reap the benefits of "Treat All". 


\section{Data availability}

Underlying data

Figshare: Matare T et study 2020 ART uptake, initiation delay and retention data, https://doi.org/10.6084/m9.figshare.c.494439921.

This project contains the following underlying data:

- ART initiation delay and retention data: Patient wise ART initiation delay and retention data of people initiated on
ART before (Q2-2015) and during (Q2-2017) "Treat All” from the 50 ePMS sites in Harare, Zimbabwe.

- $\quad$ ART uptake data: Aggregate quarterwise ART uptake data from 2014 to 2018 in Harare.

Data are available under the terms of the Creative Commons Zero "No rights reserved" data waiver (CCO 1.0 Public domain dedication).
1. UNAIDS: Global HIV statistics-Fact Sheet. Geneva, Switzerland 2019. Reference Source

2. Eholié SP, Badje A, Kouame GM, et al:: Antiretroviral treatment regardless of CD4 count: the universal answer to a contextual question. AIDS Res Ther. 2016: 13: 27

PubMed Abstract | Publisher Full Text | Free Full Text

3. World Health Organization (WHO): Guidelines Guideline on When To Start Antiretroviral Therapy and on Pre-Exposure Prophylaxis for HIV. Harare, Zimbabwe. 2015; 78 . Reference Source

4. World Health Organization (WHO): Who HIV Policy Adoption and Implementation Status in Countries. Geneva, Switzerland. 2018; 2019. Reference Source

5. Kimmel AD, Bono RS, Keiser O, et al.: Mathematical modelling to inform "treat all" implementation in sub-Saharan Africa: a scoping review. J Virus Erad. 2018; 4(Suppl 2): 47-54. PubMed Abstract | Free Full Text

6. Gosset A, Larmarange J, Mcgrath N, et al.: Retention in care trajectories of HIVpositive individuals participating in a universal test and treat programme in rural South Africa (ANRS 12249 TasP trial). J Acquir Immune Defic Syndr. 2019; 80(4): 375-385.

PubMed Abstract | Publisher Full Text | Free Full Text

7. Hendrickson CJ, Pascoe SJS, Huber AN, et al:: "My future is bright...I won't die with the cause of AIDS": ten-year patient ART outcomes and experiences in South Africa. J Int AIDS Soc. 2018; 21(10): e25184. PubMed Abstract | Publisher Full Text | Free Full Text

8. Alhaj M, Amberbir A, Singogo E, et al:: Retention on antiretroviral therapy during Universal Test and Treat implementation in Zomba district, Malawi: a retrospective cohort study. J Int AIDS Soc. 2019; 22(2): e25239. PubMed Abstract | Publisher Full Text | Free Full Text

9. Zimbawe National Statistics Agency: Zimbabwe Population Census. Harare, Zimbabwe. 2012. Reference Source

10. Ministry of Health and Child Care and National AIDS Council: 2017 Zimbabwe HIV Estimates. Harare, Zimbabwe. 2018.

Reference Source

11. Minstry of Health and Child Care: Zimbabwe Population-based HIV Impact
Assessment Report. Harare, Zimbabwe. 2016. Reference Source

12. Ministry of Health and Child Care: Guidelines for Antiretroviral Therapy for the Prevention and Treatment of HIV in Zimbabwe. Harare, Zimbabwe. 2016; 78. Reference Source

13. Ministry of Health and Child Care: Consolidated HIV and AIDS Job Aide. Harare Zimbabwe. 2017. Reference Source

14. Ministry of Health and Child Care: Guidelines for Antiretroviral Therapy for the Prevention and Treatment of HIV in Zimbabwe. Harare, Zimbabwe. 2013. Reference Source

15. UNAIDS: 90-90-90 An ambitious treatment target to help end the AIDS epidemic. Geneva, Switzerland. 2014; 33. Reference Source

16. Rufu A, Chitimbire VTS, Nzou C, et al: Implementation of the "Test and Treat" policy for newly diagnosed people living with HIV in Zimbabwe in 2017. Public Health Action. 2018; 8(3): 145-150.

Health Action. 2018; 8(3): 145-150.
PubMed Abstract | Publisher Full Text | Free Full Text

17. Brown LB, Getahun M, Ayieko J, et al:: Factors predictive of successful retention in care among HIV-infected men in a universal test-and-treat setting in Uganda and Kenya: A mixed methods analysis. PLoS One. 2019; 14(1): e0210126. PubMed Abstract | Publisher Full Text | Free Full Text

18. Magaço A, Dovel K, Cataldo F, et al.: "Good health" as a barrier and facilitator to ART initiation: a qualitative study in the era of test-and-treat in Mozambique. Cult Health Sex. 2019; 21(9): 1059-1073. PubMed Abstract | Publisher Full Text

19. Nhassengo $P$, Cataldo $F$, Magaço $A$, et al: Barriers and facilitators to the uptake of Test and Treat in Mozambique: A qualitative study on patient and provider perceptions. PLoS One. 2018; 13(12): e0205919. PubMed Abstract | Publisher Full Text | Free Full Text

20. Elul B, Lamb MR, Lahuerta M, et al:: A combination intervention strategy to improve linkage to and retention in HIV care following diagnosis in Mozambique: A cluster-randomized study. PLOS Med. 2017: 14(11): e1002433. PubMed Abstract | Publisher Full Text | Free Full Text

21. Shewade HD: Matare T et study 2020 ART uptake, initiation delay and retention data. figshare. Collection. 2020. http://www.doi.org/10.6084/m9.figshare.c.4944399.v1 


\section{Open Peer Review}

\section{Current Peer Review Status: ? ?}

\section{Version 1}

Reviewer Report 16 July 2020

https://doi.org/10.5256/f1000research.25846.r64871

(C) 2020 Okello J. This is an open access peer review report distributed under the terms of the Creative Commons Attribution License, which permits unrestricted use, distribution, and reproduction in any medium, provided the original work is properly cited.

\section{Joseph Mugisha Okello}

Uganda Research Unit, Medical Research Council/Uganda Virus Research Institute and London School of Hygiene and Tropical Medicine, Entebbe, Uganda

Thank you very much for giving me the opportunity to review this manuscript. I hope my review comments will lead to further improvement of the manuscript.

\section{General comments:}

1. The manuscript addresses important research questions about changes of uptake, time to initiation and retention.

2. Adherence to ART is an important issue in the management of patients in ART programmes. I am surprised that the authors did not look at adherence while looking at key programme indicators. Although the authors indicate how monitoring of patients using viral loads was done before and after treat all, they did not look at this as one of their study outcomes. The authors need to acknowledge this as one of the weaknesses of this study.

\section{Specific comments:}

\section{Introduction:}

1. In paragraph 2 of the introduction, the authors say that research in other countries demonstrated that after implementation of the "treat all", people on ART had better outcomes. The authors should mention these countries and specifically mention which ART outcomes were better.

2. The authors need to give more details on the $14 \%$ prevalence of HIV in Zimbabwe. The references given are for 2012, 2016 and 2018. Is the current HIV prevalence in Zimbabwe still $14 \%$ ? How was this national prevalence of HIV estimated in Zimbabwe?

3. In the introduction, the authors should mention the proportion of HIV infected people who were taking ART before the treat all policy became operational and the proportion currently 
when treat all policy is operational.

Methods:

1. Can you give more information on the 77 ART sites providing HIV diagnosis and treatment? Are these public facilities or private facilities?

2. Are there private providers of ART in Harare? If they are there, is the information captured by District health Information systems?

3. Is data on ART adherence captured at these ART treatment sites?

4. When people on ART get lost to follow up, is there anything done to establish reasons why they got lost to follow up?

\section{Discussion:}

1. You need to acknowledge the weakness of not looking at adherence in this study. You actually seem to agree with me on this point where you say "another potential reason for the observed lower retention could be deficiencies in coverage of quality adherence counselling with likely increased work load during the "treat all era".

2. You also need to recommend qualitative studies to look at why retention remained low in the treat all era in Harare compared to other studies in other countries. You rightly said you speculated.

Is the work clearly and accurately presented and does it cite the current literature? Partly

Is the study design appropriate and is the work technically sound?

Yes

Are sufficient details of methods and analysis provided to allow replication by others? Partly

If applicable, is the statistical analysis and its interpretation appropriate? Yes

Are all the source data underlying the results available to ensure full reproducibility? Yes

Are the conclusions drawn adequately supported by the results?

Yes

Competing Interests: No competing interests were disclosed.

Reviewer Expertise: epidemiology, HIV and ageing, chronic conditions 


\section{I confirm that I have read this submission and believe that I have an appropriate level of expertise to confirm that it is of an acceptable scientific standard, however I have significant reservations, as outlined above.}

\section{Author Response 28 Jul 2020}

Hemant Deepak Shewade, The Union South-East Asia Office, New Delhi, India

Thank you very much for the invaluable comments. We respond below, point by point.

\section{Reviewer:}

Thank you very much for giving me the opportunity to review this manuscript. I hope my review comments will lead to further improvement of the manuscript.

\section{Response:}

Thank you very much.

\section{Reviewer:}

General comments:

The manuscript addresses important research questions about changes of uptake, time to initiation and retention.

\section{Response:}

Thank you very much.

\section{Reviewer:}

Adherence to ART is an important issue in the management of patients in ART programmes. I am surprised that the authors did not look at adherence while looking at key programme indicators. Although the authors indicate how monitoring of patients using viral loads was done before and after treat all, they did not look at this as one of their study outcomes. The authors need to acknowledge this as one of the weaknesses of this study.

\section{Response:}

Thank you very much. The before period included April-June 2015 and during this time VL had not been introduced for routine monitoring of ART response. Hence, we were not able to document the before-after effect of "Treat All" on VL.

\section{Reviewer:}

Specific comments:

Introduction:

In paragraph 2 of the introduction, the authors say that research in other countries demonstrated that after implementation of the "treat all", people on ART had better outcomes. The authors should mention these countries and specifically mention which ART outcomes were better.

\section{Response:}

Thank you very much. We have revised the introduction section as per the advice by reviewer. The revised lines now read as follows

Studies from southern African countries have demonstrated the health and economic benefits of "Treat All". Research in rural South Africa and Malawi demonstrated that after implementation of "Treat All", people on ART had better retention in care. 


\section{Reviewer:}

The authors need to give more details on the $14 \%$ prevalence of HIV in Zimbabwe. The references given are for 2012, 2016 and 2018. Is the current HIV prevalence in Zimbabwe still 14\%? How was this national prevalence of HIV estimated in Zimbabwe?

\section{Response:}

Thank you very much. The 2018 reference is to give the updated number of PLHIV in Zimbabwe (1.3 million). The 2016 reference is the ZIMPHIA survey (Zimbabwe Populationbased HIV Impact Assessment) 2015-16 which gives the estimate for HIV prevalence among adults. The 2012 reference is the census and as it is not relevant, I have removed it from here (in the third para of introduction). The revised line now reads as follows Zimbabwe has a generalized HIV epidemic, with an estimated 1.3 million PLHIV and an HIV prevalence of $14 \%$ among adults (15-49 years) as per the ZIMPHIA survey 2015-16.

\section{Reviewer:}

In the introduction, the authors should mention the proportion of HIV infected people who were taking ART before the treat all policy became operational and the proportion currently when treat all policy is operational.

\section{Response:}

Thank you very much. The trends in uptake of ART among PLHIV has been described by every quarter in the results section (see Figure 1). Hence to avoid duplication, we are not mentioning the same in the introduction. Also, comparative analysis of ART uptake is one of the objectives of the study. Hence, we are not mentioning it in the introduction. We hope this is fine.

\section{Reviewer:}

Methods:

Can you give more information on the 77 ART sites providing HIV diagnosis and treatment? Are these public facilities or private facilities?

\section{Response:}

Thank you very much. We have clarified in the revised manuscript that these are public facilities.

\section{Reviewer:}

Are there private providers of ART in Harare? If they are there, is the information captured by District health Information systems?

\section{Response:}

Thank you very much. Information on private providers is not captured in DHIS.

\section{Reviewer:}

Is data on ART adherence captured at these ART treatment sites?

\section{Response:}

Thank you very much. Data on ART adherence is collected but is unreliable as this is based on self-reports and pill count. Furthermore this is only available for those patients who returned for their last scheduled visit hence will not account for the LTFU and transfer-out patients. 


\section{Reviewer:}

When people on ART get lost to follow up, is there anything done to establish reasons why they got lost to follow up?

\section{Response:}

Thank you very much. We have tried to speculate the reasons for this in the revised manuscript. An unpublished WHO report suggests that only $25 \%$ of those documented as LTFUs are true LTFUs. I am copy pasting the new lines added to the discussion section regarding this

High rates of LTFU before and during "Treat All" may not actually be LTFU but enrolment in a different clinic closer to home. Due to stigma and discrimination, people tend to get tested out of their area of residence where they are not known and after enrolment tend to move closer to home for treatment. Furthermore we have also added to the methods section in Paragraph 4 under the subheading "ART initiation before "Treat AII"' that patients are declared LTFU if they are not successfully traced back to care within 90 days from their last scheduled visit either by phone call or physical follow-ups by community health workers.

\section{Reviewer:}

Discussion:

You need to acknowledge the weakness of not looking at adherence in this study. You actually seem to agree with me on this point where you say "another potential reason for the observed lower retention could be deficiencies in coverage of quality adherence counselling with likely increased work load during the "treat all era".

\section{Response:}

Thank you very much. We agree with you. But as discussed before, data on ART adherence is collected but is unreliable as this is based on self-reports and pill count. Adherence would best be measured by VL testing which was not routinely available in the period prior to HIV treat All. Hence we were not in a position to compare the same before and during Treat All. Also there were large instances of missing data of CD4 count (mentioned as a limitation in second last paragraph of discussion)

\section{Reviewer:}

You also need to recommend qualitative studies to look at why retention remained low in the treat all era in Harare compared to other studies in other countries. You rightly said you speculated.

\section{Response:}

Thank you very much. We have included a line of qualitative systematic enquiry in discussion section.

The programme should consider qualitative systematic enquiry into why the retention did not improve during "Treat All" in Harare.

\section{Competing Interests: Nil}




\section{https://doi.org/10.5256/f1000research.25846.r62743}

(C) 2020 Dongmo-Nguimfack B. This is an open access peer review report distributed under the terms of the Creative Commons Attribution License, which permits unrestricted use, distribution, and reproduction in any medium, provided the original work is properly cited.

\section{Boniface Dongmo-Nguimfack (iD}

Department of HIV/AIDS, World Health Organization, Geneva, Switzerland

The study was designed to answer the question on uptake and retention comparing the before treat all period to the treat all period. Statistically speaking the analysis was well done and reflects the pure data analysis as well as the outcome of the analysis.

The paper lacks a clear disclaimer of the limitation(s) of the study.

No information on the lack of tracing one patient from one clinic to the other as soon as they get outside the ePMS.

Lack of information on the mobility of patients in the city and the country in general.

Lack of information on how easy or difficult it is to enroll in a new clinic.

The lack of patient unique identifier outside the ePMS clinics.

The difficulty when you reach the $80 \%$ enrolment to find the last $20 \%$.

No comparative analysis on how easy or difficult the enrolment and the treatment was within Harare between the before treat all period to the treat all period.

The methodology does not reflect the reality of the country as there are still stigma and discrimination in the country and people tend to get tested out of their area of residence where they are not known and after enrollment tend to move closer to home for treatment which may justify the high rate of LTFU which actually may not be LTFU but enrollment in a different clinic closer to home.

The WHO not-published survey in Harare in 2018 shows that out of 100 LTFU only 25 were LTFU, 75 have just changed clinics or regions.

It is quite easy in Harare to move from one clinic to another clinic (the reason why the duplication in number is so high).

WHO recommends index tracing and testing to move from $70 \%$ to $95 \%$ which is the new target.

Is the work clearly and accurately presented and does it cite the current literature? Partly

Is the study design appropriate and is the work technically sound? 
Partly

Are sufficient details of methods and analysis provided to allow replication by others? Yes

If applicable, is the statistical analysis and its interpretation appropriate? Yes

Are all the source data underlying the results available to ensure full reproducibility? Yes

Are the conclusions drawn adequately supported by the results? Yes

Competing Interests: No competing interests were disclosed.

Reviewer Expertise: I am an economist and member of the HIV guideline Technical Working Group of the WHO

I confirm that I have read this submission and believe that I have an appropriate level of expertise to confirm that it is of an acceptable scientific standard, however I have significant reservations, as outlined above.

\section{Author Response 28 Jul 2020}

Hemant Deepak Shewade, The Union South-East Asia Office, New Delhi, India

Thank you very much for your comments. This has helped us improve our manuscript. We hope the revised manuscript now meets your expectations. Point by point response to your comments is provided below

Reviewer:

The study was designed to answer the question on uptake and retention comparing the before treat all period to the treat all period. Statistically speaking the analysis was well done and reflects the pure data analysis as well as the outcome of the analysis.

Response:

Thank you very much for the constructive comment.

Reviewer:

The paper lacks a clear disclaimer of the limitation(s) of the study.

Response:

Thank you very much. The strengths and limitations have been mentioned in the second last paragraph of discussion.

Reviewer:

No information on the lack of tracing one patient from one clinic to the other as soon as they get outside the ePMS. 


\section{Response:}

Thank you very much. We agree with the reviewer here. We have added this as a limitation. We did not have details about what happened to those that were transferred out. Alive and on treatment and transferred out combined were combined as "retained in care". Patients that were transferred out were censored on their last recorded visit to ART site.

\section{Reviewer:}

Lack of information on the mobility of patients in the city and the country in general. Response:

Thank you very much. Yes, this is a limitation and is explained in second from last paragraph of the discussion section.

\section{Reviewer:}

Lack of information on how easy or difficult it is to enrol in a new clinic.

\section{Response:}

Thank you very much. We have added the following information under the methods subheading "ART initiation before "Treat All":

If a patient officially transfers-out to another ART clinic, they are issued with a transfer-out letter for presentation at the receiving ART clinic and they maintain their ART number. In other instances, patients may unofficially transfer out to another health facility without being assigned a transfer-out letter and are therefore declared lost to follow-up at their original facility if they exceed 90 days after their last scheduled clinic or drug pick-up visit and all attempts to trace them back to care have been futile. The patients will often present at the transfer-in facility with a patient-held ART booklet which indicates their previous medical history and therefore continue receiving ART care whilst also maintaining their ART number. Alternatively, if no evidence of previous treatment is provided, they are offered an HIV test and subsequently assigned a new ART number and treated as new ART client

\section{Reviewer:}

The lack of patient unique identifier outside the ePMS clinics.

\section{Response:}

Thank you very much. We agree with the reviewer. However, we included only the ePMS sites which had electronic data for analysis. Hence, this was beyond the scope of our study. We also respond to your comment in the methods subheading "ART initiation before "Treat All'"'!

\section{Reviewer:}

The difficulty when you reach the $80 \%$ enrolment to find the last $20 \%$.

\section{Response:}

Thank you very much. We agree with the reviewer here based on our programme experience.

\section{Reviewer:}

No comparative analysis on how easy or difficult the enrolment and the treatment was within Harare between the before treat all period to the treat all period.

\section{Response:}

We have added some additional information in the methods section. Prior to "Treat All" 
psychosocial criteria for ART initiation, included completion of prescribed counselling sessions and an assessment of adherence to CPT in the past 3 months with CPT adherence being used to assess the likelihood that the patient would adhere to ART. Whereas in the Treat All era, additional changes included an emphasis for health workers to provide adequate counselling and start ART within a week with exception of pregnant and breastfeeding women who were to be started on ART on the same day of HIV diagnosis. However, for those patients who are not ready yet to start ART, they should receive on-going counselling and support.

\section{Reviewer:}

The methodology does not reflect the reality of the country as there are still stigma and discrimination in the country and people tend to get tested out of their area of residence where they are not known and after enrolment tend to move closer to home for treatment which may justify the high rate of LTFU which actually may not be LTFU but enrolment in a different clinic closer to home.

\section{Response:}

Thank you very much. We have included this point in paragraph four of the discussion section in the revised manuscript. We have copied it below for your kind perusal High rates of LTFU before and during "Treat All" may not actually be LTFU but enrolment in a different clinic closer to home. Due to stigma and discrimination, people tend to get tested out of their area of residence where they are not known and after enrolment tend to move closer to home for treatment.

\section{Reviewer:}

The WHO not-published survey in Harare in 2018 shows that out of 100 LTFU only 25 were LTFU, 75 have just changed clinics or regions.

\section{Response:}

Thank you very much. This supports our revision in the fourth paragraph of discussion section.

\section{Reviewer:}

It is quite easy in Harare to move from one clinic to another clinic (the reason why the duplication in number is so high).

Response:

Thank you very much. We agree with the reviewer.

\section{Reviewer:}

WHO recommends index tracing and testing to move from $70 \%$ to $95 \%$ which is the new target.

\section{Response:}

Thank you very much. We agree with the reviewer. Index tracing and testing will help achieving the first (90) or the first (95) of the UNAIDS target. This deals with what proportion of expected HIV positive should be diagnosed. Our study dealt (objective on ART uptake) with the second 90 or 95 which states what percentage of diagnosed PLHIV should be started on ART. We hope this is fine. 


\section{Competing Interests: Nil}

The benefits of publishing with F1000Research:

- Your article is published within days, with no editorial bias

- You can publish traditional articles, null/negative results, case reports, data notes and more

- The peer review process is transparent and collaborative

- Your article is indexed in PubMed after passing peer review

- Dedicated customer support at every stage

For pre-submission enquiries, contact research@f1000.com 